\title{
La semiótica visual como estrategia de neuromarketing en textos digitales de promoción turística y su importancia para la traducción
}

Visual semiotics as a neuromarketing strategy in tourist information and promotion digital texts, and its importance for translation activity (Spanish, French and Italian)

\section{Gisella Policastro Ponce}

Universidad de Córdoba
ONOMÁZEIN | Número especial VII - Discurso turístico, lenguas y traducción: 224-241

DOI: 10.7764/onomazein.ne7.05

ISSN: 0718-5758

\section{(c) $(i)$}

Gisella Policastro Ponce: Departamento de Ciencias Sociales, Filosofía, Geografía, Traducción e Interpretación. Universidad de Córdoba. ORCID:0000-0002-1446-0206. | E-mail: gisella.policastro@uco.es

Fecha de recepción: julio de 2019

Fecha de aceptación: abril de 2020 


\section{Resumen}

El traductor turístico debe tener presente que la heterogeneidad e interdisciplinariedad que caracterizan al lenguaje del turismo (Calvi, 2006) requieren ir más allá de lo puramente lingüístico, en la medida en que para poder crear en el consumidor-turista algún tipo de motivación que le impulse a manifestar una conducta determinada es necesario un procesamiento previo de la información percibida a partir de estímulos verbales y no verbales (Alonso Rivas y Grande Esteban, 2013). El presente trabajo reflexiona sobre los procesos cognitivos que figuran detrás de una decisión en la aplicación de estrategias de neuromarketing en textos turísticos y cómo estos se materializan a través del uso de dos recursos semióticos visuales: la imagen y el color. En esencia, se trata de una imbricación conceptual e interpretativa que se deberá tener en consideración al realizar la traducción de este tipo de textos.

Palabras clave: semiótica visual; traducción turística; neuromarketing; promoción turística; procesos cognitivos.

\section{Abstract}

The translator of texts from the tourist sector must bear in mind the heterogeneity and interdisciplinary nature of the language of tourism (Calvi, 2006), which requires action beyond the purely linguistic. In order to create some kind of motivation which drives the consumer-tourist to act in a certain way, it is necessary to pre-process the perceived information from verbal and non-verbal stimuli (Alonso Rivas \& Grande Esteban, 2013). This paper aims to discuss the cognitive processes behind a decision when applying neuromarketing strategies to tourism texts, and how these come about through two visual semiotic resources: image and colour. In essence, it is a conceptual and interpretative overlap that should be taken into consideration when translating this type of text.

Keywords: visual semiotics; tourist translation; neuromarketing; tourist promotion; cognitive processes. 


\section{Introducción}

El antiguo director de planificación estratégica de la premiada agencia de publicidad SCPF, Antonio Núñez, defiende que "comprar no es una cuestión de lógica ni de razón. Lo que determina nuestras decisiones son las emociones, que pueden ser positivas o negativas en función el input recibido", y considera además que "la atención de los consumidores no se capta mediante argumentos racionales, sino a través de imágenes que emocionen”. Esta última afirmación subraya la importancia de la imagen como elemento para captar la emoción del consumidor, que es en definitiva el propósito último de todo texto promocional, en tanto que, en palabras de Antonio Nuñez, "cuanto más intensa sea la emoción más profunda será la conexión neurológica conseguida en el cerebro del consumidor en potencia" (citado en Vilaseca, 2006).

Lo anteriormente expuesto nos condujo a enfocar nuestro estudio desde la perspectiva del neuromarketing promocional con el propósito de poner en evidencia determinados elementos no verbales, a saber, ciertos recursos semióticos visuales que complementan el significado del contenido lingüístico promocional de los textos turísticos digitales apelando a los sentidos del consumidor. Se trata de una metodología concebida para crear todo tipo de experiencias en el turista, de esta forma captar su atención, persuadirlo y, en definitiva, "fidelizar al cliente con su producto". Precisamente, nuestro estudio se centra en determinar y analizar concretamente dos elementos semióticos perceptibles a través de la visión del lector: la imagen y el color, considerados en su relación mutua.

Partimos de la premisa de que la elección de una imagen o un color determinados en cualquier texto de información y promoción turística se basa en métodos y técnicas de neuromarketing con un propósito promocional que se materializa a través de la estimulación sensorial del consumidor.

La identificación de las funciones promocionales de estos recursos semióticos forma parte del proceso de interpretación que caracteriza toda actividad traductora. Ahora bien, dicha apreciación atiende a la representación no lingüística de un significado que se expresa a través de las percepciones. El autor del texto original apela a los sentidos de su público meta activando sus procesos cognitivos y creando un determinado efecto comunicativo, que el traductor deberá saber interpretar y trasladar a la cultura meta. La aparente simplicidad del proceso exige por parte del traductor un conocimiento profundo y multidisciplinar que implica el dominio de técnicas de neuromarketing aplicadas a cada elemento semiótico para que cumplan una función promocional determinada.

$1 \quad$ Expresión propia del lenguaje del marketing. 


\section{Neuromarketing: modelo de innovación emergente}

"El marketing no es una batalla entre productos, sino de percepciones". Esta afamada proposición de los notorios publicistas norteamericanos Ries y Trout define la "ley de la percepción", que constituye una de Las 22 leyes inmutables del marketing (1994)2, una de las obras más distinguidas de estos autores y que recoge las reglas básicas que definen sus planteamientos.

Al Ries y Jack Trout rompieron paradigmas y demostraron que la verdadera batalla se libra en la mente de los consumidores, tal y como recoge otra de sus leyes, la "ley de la mente": "Es mejor ser el primero en la mente que el primero en el punto de venta". Conseguir dicha presencia en la mente del consumidor requiere un conocimiento integral del comportamiento, necesidades, preferencias e intereses del consumidor, con el propósito de activar los procesos cognitivos que permiten interpretar y construir el significado en función del tipo de estímulo recibido.

Gracias al desarrollo avanzado de las nuevas tecnologías y su aplicación en el ámbito de la promoción, junto con los importantes avances obtenidos en materias como la neurociencia, la antropología social o la neurolingüística, es posible comprender el comportamiento del cerebro humano ante determinados estímulos con el propósito de fomentar estrategias de marketing más efectivas y productivas que transciendan la persuasión momentánea del que recibe el estímulo y consigan crear en el usuario un "vínculo afectivo con el producto" (Soler Guitián, 2017: 77), marca o idea que sea objeto de promoción. Llegados a este punto, podemos constatar que la presencia de la neurociencia en la toma de decisiones, la percepción de emociones y la respuesta ante estímulos por parte de los consumidores es una realidad que se ha materializado en la aplicación de las técnicas de la neurociencia en el marketing y cuya sinergia ha dado lugar a una nueva ciencia: el neuromarketing.

A pesar de no estar todavía recogido en el Diccionario de la lengua española, son varios los autores que han facilitado diversas definiciones del término, todas ellas muy similares entre sí y compartiendo un mismo enfoque: se trata de una disciplina moderna que estudia los patrones de actividad cerebral implicados en la conducta del consumidor en base a la respuesta ante diferentes estímulos recibidos dentro del campo de acción del marketing.

Braidot y Braidot (2006) concretan que el neuromarketing tiene como finalidad "incorporar los conocimientos sobre los procesos cerebrales para mejorar la eficacia de cada una de las acciones que determinan la relación de una organización con sus clientes" y, a tal efecto, "aplica

2 Junto con Posicionamiento. La batalla por tu mente (1981), ambas obras se han convertido en el manual de instrucciones básico para cualquier estrategia de promoción, puesto que recogen las premisas esenciales del marketing de nuestro siglo XXI. 
novedosas y complejas técnicas neurocientíficas a la investigación de todos los aspectos que involucra su campo de acción", lo que implica, por tanto, una "indagación de todos los factores que determinan el comportamiento de compra y consumo en segmentos específicos del mercado y en el cliente individual" (2006: 17).

Klaric (2016) define el neuromarketing como "la ciencia que te ayuda a poder predecir si el estímulo, la comunicación, el producto o el servicio está comunicando de forma correcta sus beneficios". En su libro Véndale a la mente, no a la gente, el autor nos muestra cómo esta poderosa herramienta conecta entre sí y de forma estratégica productos, servicios, marcas o categorías con la mente del consumidor, mediante el estudio de "los estímulos y las cosas que le gustan al cerebro" (2015: 12).

Reiman (2001), al que se le atribuye (junto a Lewis3) el auge de este campo del conocimiento, sintetiza en breves palabras la relevancia del uso de la neurociencia en el mundo de los negocios: "No brain, no gain"4.

En la nueva era del marketing y de las nuevas tecnologías, la inclusión de técnicas y estudios sobre el funcionamiento del cerebro y operaciones mentales con fines comerciales ha supuesto una revolución y todo un desafío del concepto del marketing tradicional. En particular, a partir de la década de los noventa comienza a suscitarse un amplio interés por el conocimiento del cerebro. Posteriormente, a partir de principios del nuevo siglo XXI, los estudios adquieren un carácter más empírico y se desarrolla una interacción entre las investigaciones científicas en torno a la neurociencia y su aplicación práctica a otras disciplinas. Cabe matizar que el concepto del marketing siempre se ha caracterizado por su interdisciplinariedad, al nutrirse de diversas áreas de conocimiento, tales como la economía, la publicidad, la sociología, la psicología o la antropología; por consiguiente, resultaba necesaria su imbricación con la neurociencia en un contexto en el que comenzaban a surgir preguntas tales como ¿cuáles son las motivaciones que llevan al consumidor a adquirir un producto y no otro? o ¿qué criterio determina el poder de decisión?

Braidot (2000: 33) responde con una explicación biológica a estas preguntas:

Lo que el cerebro recibe es un conjunto de señales eléctricas que se ocupa de traducir para otorgar significado a la realidad que percibimos. En este proceso intervienen no sólo los órganos sensoriales (como los ojos o el oído), sino también las cortezas sensoriales (como la corteza visual y la corteza auditiva).

3 David Lewis es considerado por muchos el padre del neuromarketing por ser uno de los pioneros en aplicar la neurociencia y neurorrealimentación al campo del marketing.

4 Parafraseando el proverbio inglés no pain, no gain, se ha convertido en una expresión de uso común en este ámbito. 
A su vez, Bergen (2014) nos explica que los seres humanos "damos cuerpo al significado de forma distinta: tenemos representaciones visuales diferentes" (2014: 235) del aspecto de la realidad en función de nuestra experiencia individual, lo que nos lleva a interpretar el lenguaje o las palabras de manera distinta, puesto que

las simulaciones encarnadas ${ }^{5}$ que construimos no siguen una plantilla universal, están profundamente impregnadas no solo en nuestras experiencias personales, sino de las que adquirimos como consecuencia de pertenecer a una determinada cultura (2014: 241).

Este autor pone un ejemplo práctico muy simple: el verbo conducir es fácilmente traducible en diferentes idiomas; sin embargo, su interpretación en cada cultura puede ser diversa. En España, por ejemplo, nos imaginaremos a una persona dentro de un vehículo en el lado izquierdo del coche, mientras que, en Inglaterra, la imagen que tendrán de un conductor estará posicionada en el lado derecho. Ante este hecho, estamos de acuerdo con las palabras de Bergen (2014: 235):

[C]uando estas experiencias difieren sistemáticamente entre las distintas culturas, la consecuencia en principio podría ser que las mismas palabras se interpreten de manera distinta; las mismas palabras pueden impulsar simulaciones encarnadas diferentes en distintas poblaciones.

De forma análoga a lo recogido en la cita anterior, se considera que el ser humano interpreta la realidad mediante representaciones mentales a partir de lo que se percibe mediante nuestro sistema perceptual, conformando nuestra estructura conceptual. Será, por tanto, el traductor el responsable de interpretar la conexión entre un concepto expresado en una lengua A y la percepción asociada al mismo, que generará una respuesta por parte del lector de dicha lengua A. Una vez identificada por su parte dicha relación de significado, deberá trasladar dicho concepto a una lengua $B$, de tal manera que la representación mental del lector $A$ sea la misma que la del lector $B$, a pesar de las diferencias culturales, lingüísticas, conceptuales y cognitivas.

La descodificación de un mensaje no verbal que se encuentra íntimamente vinculado a la conceptualización cultural se presenta como un reto para el traductor a la hora de adaptar este tipo de elementos multimodales a la cultura meta, puesto que implica conocer la sociedad de consumo, respetar sus valores, sus hábitos y construir un significado no verbal que, sin

5 El concepto "simulación encarnada”, que comenzó a forjarse durante los años noventa, hace referencia a la capacidad que tiene la mente para experimentar de forma simulada lo que se describe mediante elementos lingüísticos, al objeto de interpretar el mensaje que se nos haya transmitido. De acuerdo con la hipótesis de la simulación encarnada, para interpretar el significado de un concepto, construimos en nuestra mente experiencias a través de los sentidos (olfato, gusto, tacto, vista y oído) que generan percepciones y acciones diferentes en cada individuo, haciendo uso de diferentes sistemas cognitivos. 
duda alguna, no puede limitarse a lo meramente lingüístico. Es en este punto donde entran en juego los sistemas de interacción semiótica.

\section{El código visual en neuromarketing}

Una considerable cantidad de literatura científica muy heterogénea ha sido publicada a propósito del código visual y su papel protagonista en la actividad turística (Miossec, 1977; Pearce, 1982; Pritchard y Morgan, 2001; Pike, 2002; Camprubí y otros, 2009; entre otros), destacando especialmente el estudio teórico de Gallarza y otros (2002), Tasci y otros (2007) y Hernández Ramírez (2008) en torno a la combinación de ambos conceptos. Sin embargo, son escasos los estudios sistemáticos con respecto a la presencia de elementos del código visual en los textos turísticos, su finalidad y los procesos cognitivos relacionados con el neuromarketing.

Habida cuenta de que la representación gráfica es incluso anterior a la aparición del lenguaje escrito, no es nuestra intención revisar la bibliografía en torno a dicho concepto. En línea con lo anteriormente expuesto, nuestra atención se centrará en dos elementos comunicantes no verbales utilizados en neuromarketing y que afectan a la percepción visual: Ia imagen y el color. Nuestro propósito es estudiar la "semiótica de la imagen visual" (Magariños de Morentin, 2001) con la intencionalidad de conocer cómo funciona y, por tanto, ser capaces de interpretar su mensaje y trasladarlo correctamente a otro idioma. La efectividad de una situación comunicativa dependerá de que exista un entendimiento entre emisor y receptor, y de que ambos utilicen el mismo o los mismos códigos.

Precisamente, el proceso de descodificación que tiene lugar en nuestro cerebro, en concreto en el subconsciente, se lleva a cabo cuando se trata de interpretar de forma racional el modo en el que percibimos las emociones y en el que respondemos ante determinados estímulos. Los estudios de neuromarketing ponen de manifiesto que el diseño de los productos, así como las campañas de publicidad, marketing y promoción en torno a los mismos, se están adaptando progresivamente y de forma exponencial a las respuestas emocionales de los usuarios. La clave radica en la utilización del mismo código de comunicación que apele a un mismo propósito.

En este caso, en el contexto turístico, y concretamente en el marco de la promoción, la situación comunicativa muestra especial interés por "apelar a las sensaciones y vivencias de los receptores para activar sus procesos cognitivos" (Llorens Simón, 2017: 296) y suscitar cierta afinidad con el consumidor, a fin de que este se encuentre cómodo, identifique aspectos familiares y deseables, gestándose un vínculo estratégico entre el producto o la experiencia y el consumidor-turista.

La planificación estratégica propia del neuromarketing tiene como doble propósito la apelación a las emociones y la creación de una experiencia en el consumidor mediante la acti- 
vación de procesos cognitivos. Ello implica, en nuestro caso, la puesta en práctica de un uso consciente de la plasmación gráfica de un elemento visual como opción para favorecer empatía y persuasión en el ámbito de la experiencia turística. Para esto se utilizan técnicas biométricas de neuromarketing, mediante la técnica de electroencefalograma (EEG), que miden las ondas cerebrales atendiendo a tres parámetros asociados a la actividad cerebral: atención, emoción y memoria, como analizaremos más adelante.

No podemos olvidar, además, que el cerebro se encuentra biológicamente diseñado para interpretar los estímulos visuales. Según Gibson (1966), contamos con cinco sistemas perceptuales (sistema de orientación básica, sistema háptico, sistema del gusto-olfato, sistema auditivo y sistema visual) y todos ellos se encuentran integrados entre sí. Con todo, como señala Bergen (2014: 78), el sentido de la vista "es nuestra principal forma de recabar información del mundo", y lo "asociamos más estrechamente a la mente". De ahí que hablemos de "representaciones mentales" al referirnos al papel de las imágenes en el procesamiento de la información.

Concretamente, el sistema perceptual visual está íntimamente relacionado con el desarrollo cognitivo y la comprensión. Hacemos uso del sistema visual "no solo para detectar las cosas visibles del mundo real, sino también para simular mentalmente cosas que no están presentes” (Bergen, 2014: 79), como mecanismo de interpretación, comprensión o aprendizaje. El simple hecho de leer o pronunciar una oración o mencionar un objeto provoca la representación de estímulos en nuestra corteza cerebral y la construcción de simulaciones visuales en nuestra mente.

La transmisión de un mensaje a través del código visual tendrá un impacto más efectivo en su posterior interpretación por parte del sujeto objetivo que en el caso de que se empleara otro código o se apelase a otro sistema de percepción. Dicha tarea requiere prestar atención a determinados factores y elementos implicados en el sistema perceptual visual, como procederemos a abordar en los siguientes apartados.

\subsection{La imagen turística}

"La imagen turística puede ser considerada como el motor de la actividad turística" (Santillán, 2010: 72).

Resulta imposible imaginar una campaña de promoción turística en la que no aparezca ni una sola representación visual del destino en cuestión, del mismo modo que no concebimos un anuncio publicitario que no haga alusión al producto que desea promocionar. Más aún en la "cultura de lo visual" o la "era de la imagen" en la que vivimos.

La imagen, entendida como proyección de la realidad, es la esencia de la experiencia turística que crea un vínculo emocional entre el turista y el destino y, a su vez, es el eje cardinal del marketing turístico. En torno a la imagen turística se articula el “imaginario visual”, entendido 
como una construcción social que configura una identidad idealizada del destino turístico en un contexto sociocultural dado y que influye en la percepción y consiguiente toma de decisiones turísticas.

Antes de continuar avanzado, conviene explicar que existe una importante distinción entre las imágenes percibidas y las imágenes emitidas. La literatura científica ha usado varias notaciones para referirse a ambos conceptos, si bien la interpretación que hacen Galí Espelt y Donaire (2006: 124) de ambos conceptos nos parece la más idónea. Según los autores, las imágenes emitidas "son una reproducción de signos con significado que ha estado socialmente construida y diseminada", mientras que las imágenes percibas por los turistas son "el conjunto de valores, ideas, ideologías, de imágenes preconcebidas, de experiencias, de conocimientos, de percepciones individuales, introspecciones subjetivas, únicas, que se construyen en la mente de los visitantes".

Como postula Miossec (1977) ${ }^{6}$, existen tres tipos de imágenes emitidas: a) universales, que hacen referencia al imaginario colectivo; b) inducidas, aquellas que se consideran formuladas por determinados agentes turísticos; y c) accidentales o efímeras, que describen aquellas imágenes turísticas que "pueden generar de forma puntual la imagen colectiva de un lugar" (citado en Azeglio y Gandara, 2010: § 12).

En el presente estudio, a priori, el foco de atención de nuestro trabajo se centra en las imágenes emitidas como resultado de acciones de neuromarketing por promotores turísticos y, en particular, nuestra investigación apunta a las imágenes inducidas, creadas específicamente con el fin de potenciar el consumo turístico. No obstante, en lo que respecta al proceso de traducción, se deberán tener en cuenta las imágenes emitidas en la lengua de origen y las imágenes percibidas por el público meta: una composición que supone todo un reto para el traductor turístico.

\subsection{El color o código cromático}

“(...) la percepción del color es la parte simple más emotiva del proceso visual, tiene una gran fuerza y puede emplearse para expresar y reforzar la información visual” (Dondis, 2002: 69).

El poder expresivo del color, resultante de la percepción de los diferentes cambios de luz por parte del ser humano, hace que este genere una respuesta emocional concreta. La simbología cromática no parte únicamente de la observación racional, sino que implica una esfera intelectual, social, moral, estética, imaginativa (Pagani, 2001). Son numerosas las consideraciones atribuidas a la interpretación del significado de los colores, que es considerada en neuro-

6 Inspirado en el modelo de proceso de la imagen de Gunn (1972). 
marketing un elemento estimulador de activación emocional y, tal como se ha señalado con anterioridad, tiene un impacto visual en el usuario, pudiendo llegar a crear un sentimiento de atracción o de rechazo?

Lo relevante es la proyección sensorial y psicológica de los colores, que es capaz de transmitir mensajes muy diversos: invita a experimentar diferentes sensaciones, realza las propiedades y atributos de un determinado producto, en ocasiones creando un mayor realismo. Asimismo, tiene asociado un simbolismo particular vinculado a cuestiones de tipo cultural y/o social en cuanto artefacto cultural que marca y define su construcción social, su significado y su simbolismo determinado por su interpretación cultural ${ }^{8}$.

Como señalan Ferrer Franquesa y Gómez Fontanills (2013: § 1-2),

[e] sistema de percepción visual no ha cambiado nada, pero nuestro bagaje cultural sí. Nuestra interpretación del color y la forma como el color incide en nuestra construcción de significados está llena de esta carga cultural. De hecho, la propia noción de color ha evolucionado a lo largo de la historia y las culturas.

En las estrategias de neuromarketing aplicadas a la actividad turística, el color es un elemento más del acto comunicativo promocional que se utiliza como herramienta tendente a afectar en la percepción del usuario con el propósito de que este se comporte de una determinada forma, tratando a su vez de crear un interés positivo respecto del destino turístico que se desea promocionar. De hecho, una de las manifestaciones físicas de la marca de un producto es la identificación de colores corporativos, que contribuyen a que el consumidor asocie mentalmente un color a una compañía o productos determinados.

No obstante, la interpretación del estímulo visual generado por el color está condicionada por el bagaje cultural. El código cromático se configura como un sistema de comunicación que emplea el color como símbolo de expresión que puede verse modificado a merced del contexto o del momento.

Un aspecto interesante descubierto por Conway y otros (2010) es el hecho de que, en términos de estimulación cerebral, no existe una misma categorización cromática, pudiéndose deber

7 Por ejemplo, el blanco se utiliza tanto en las imágenes turísticas como color de fondo para la visualización de cierta información con un significado simbólico con el que se pretende transmitir paz, transparencia, alegría. Este color tiene, en el mundo occidental, un aspecto simbólico diverso al de países orientales como China o Japón, donde el blanco se asocia a la tristeza. Por su parte, el verde se asocia a la naturaleza en Occidente. Sin embargo, en ciertos países asiáticos, es símbolo de enfermedad.

8 Otra cuestión bien distinta es la clasificación cromática, que es universal con independencia de la cultura o el lenguaje en el que se utilice. 
al hecho de que existe un mayor número de neuronas que procesan determinados colores en detrimento de otros; es decir, no todos los colores producen el mismo nivel de estimulación cerebral. Junto con los aspectos fisiológicos o culturales, este es uno más de los múltiples factores sensoriales que intervienen en la percepción cerebral del color.

Caivano (1995, 2001, 2005) propone una metodología innovadora en la que contempla el color, junto con la cesía’, como elementos semióticos considerados como unidades de representación y significación. Para este autor, el color se entiende como "la percepción de la distribución espectral de la radiación visible, lo que produce las sensaciones cromáticas elementales” (2001: 90), y la cesía es "el aspecto de la visión que registra las diferentes formas de distribución de la luz en el espacio" (2001: 90). Si bien el color es perceptible por los sentidos, dicha percepción puede ser interpretable a través de un lenguaje cromático determinado por una cultura o sociedad concreta, mientras que la cesía genera sensaciones visuales que suelen ser percibidas de forma inconsciente, asociadas al modo en el que nuestro sistema visual procesa dichos estímulos resultantes de la incidencia de la radiación visible sobre un objeto.

Asimismo, Caivano conjuga la percepción de lo visual con la interpretación de su significado, trascendiendo hacia el plano mental, una percepción que es precisamente uno de los hitos del presente estudio:

El conocimiento que tenemos del mundo que nos rodea se basa en la significación que otorgamos a partes diferenciadas del mismo; todo lo que no es significativo está fuera del alcance del conocimiento. Ciertas partes de nuestro entorno son reconocidas como entidades visualmente organizadas. El reconocer una organización visual implica una operación semiótica mediante la cual adscribimos a algo algún tipo de sentido, orden o relación entre sus partes (Caivano, 2005: 113).

Por tanto, en el presente estudio, el código cromático será identificado sobre la base de la perspectiva planteada por Caivano, es decir, como objetos visuales desde un punto de vista semiótico, entendiendo que, como afirman Kress y Van Leeuwen (2001: 1), "dentro de un dominio sociocultural dado, el mismo significado puede expresarse muchas veces en distintas formas semióticas".

\section{La importancia de la imagen y el color como estrategias de neuromarketing turístico: su importancia para la traducción turística}

Centrándonos en el ámbito que nos ocupa, exponemos a continuación cuáles son, a nuestro juicio, las principales estrategias basadas en el neuromarketing aplicadas a la imagen turísti-

9 Concepto acuñado por Jannello (1984: 1), considerado uno de los pioneros en la categorización de la experiencia visual. Por motivos de espacio, no contemplaremos este recurso semiótico dentro de nuestro estudio, si bien se contempla como línea de estudio futura. 
ca y al código cromático en textos de promoción turística y su importancia para la traducción turística. En concordancia con lo expuesto con anterioridad, tomaremos como referencia las tres variables antes mencionadas: atención, emoción y memoria.

Debido a limitaciones prácticas, puesto que resultaría demasiado extenso abordar en profundidad cada uno de los posibles supuestos que podemos encontrar, nos limitaremos a exponer aquellos ejemplos que hemos considerado más representativos. Nuestro propósito es identificar, desde una aproximación teórica, la función promocional que cumplen la imagen y el color en un texto de promoción turística, desde la perspectiva del neuromarketing, con la intención de contribuir a una mejora interpretativa del mensaje que estos recursos transmiten, en beneficio del traductor.

\section{Atención}

\section{ESTRATEGIAS}

Uso de imágenes conocidas o identificables por el consumidor-turista.

Presencia de imágenes llamativas o que hacen referencia a dos realidades contrapuestas; contraste entre imágenes virtuales y reales; recurrencia a metáforas visuales, contraste cromático intenso o aplicación de dos colores pertenecientes a gamas cromáticas distintas (cálidas y frías).

\section{FUNCIÓN PROMOCIONAL BASADA EN NEUROMARKETING}

El cerebro humano interpreta la realidad mediante la asociación de lo conocido con lo innovador. El realismo o la identificación del usuario con la imagen que observa se traduce en una mayor atención o atracción, fomentando la seducción sensorial.

Como fórmula para captar la atención, se aplican técnicas enfáticas y de contraste (mediante ciertas figuras retóricas, como la antífrasis, metáforas o antítesis) utilizadas en la gramática visual y también en neuromarketing. Este tipo de estímulos son muy atractivos para nuestro cerebro (concretamente para el cerebro reptiliano ${ }^{10}$ ), que se activa y reacciona de manera subconsciente ante los cambios, activando mecanismos de alerta.

Asimismo, teniendo presente que ciertos objetos llevan intrínsecamente asociados un cromatismo definido (p. ej.: el césped es verde, el agua es azul, las nubes son blancas o grises, etc.), la recurrencia al contraste cromático es una técnica de neuromarketing que implica un alto nivel de percepción y gran carga expresiva que persigue alcanzar una gran pregnancia del mensaje de forma inconsciente.

\section{Emoción}

Imágenes que representan enclaves perfectos e idealizados, fotografías con mejoras estéticas notables, re-
La idealización del lugar que se desea promocionar es una característica básica del imaginario turístico. Embellecer y realzar las propiedades de la imagen turística es una de las principales funciones en neuromarketing, en ocasiones exagerando determinadas cuali-

10 El modelo del cerebro triúnico o triuno, formulado por Paul MacLean (1990), plantea una estructura cerebral dividida en tres sistemas: reptiliano o primitivo, límbico o emocional, neocórtex o racional. 
currencia a gamas cromáticas que generan una sensación placentera (en función de los criterios culturales); buena calidad cromática; colores intensos y brillantes. En definitiva, crear una experiencia emocional positiva a través de la correcta combinación entre la imagen y el color.

Juegos de luces (relacionados con la cesía) combinados con determinados colores, creando diversas sensaciones, empleándose tanto iluminación natural como artificial. dades mediante la hipérbole. En este caso, se trata de enfatizar la belleza del destino turístico, generar una sensación placentera y producir emociones positivas y atrayentes.

En la neurociencia, hablamos del "mecanismo de recompensa" cuando se crean experiencias placenteras que sugieren emociones agradables, lo que activa el circuito cerebral del placer provocando que nuestro cerebro genere altos niveles de dopamina.

Retomando la idea de la asociación, este circuito cerebral se activa cuando observamos algo en el exterior que, con anterioridad, nos ha generado algún tipo de satisfacción y, por tanto, asociamos dicho estímulo a la conducta placentera. Esto activa de forma inmediata nuestro deseo de satisfacer dicha necesidad.

Los contextos de iluminación y color articulan un vínculo que conjuga la percepción por parte de nuestra visión y el significado que esta genera. La refracción, absorción y reflexión de la luz sobre los objetos inciden en la percepción cromática, de manera que se conjugan estratégicamente con el propósito de provocar sensaciones placenteras en el turista.

\section{Memoria}

Imágenes de la vida cotidiana
Generan en el turista una sensación de cercanía y facilitan la recreación mental, al existir una proximidad con la realidad representada. Es lo que en neuromarketing se conoce como "diseño empático"1.

En función del tipo de turista al que se desee atraer, se representará un entorno o escena determinados, evocando experiencias cotidianas que susciten en el consumidor-turista una sensación de asociación a su realidad personal y así crear una mayor atracción e identificación personal con la escena recreada. Una tarea que apela a la memoria e influye en el recuerdo, alcanzando, por tanto, un lugar privilegiado en la mente del turista.

El "turismo de colores", un concepto innovador que vincula el neuromarketing de las sensaciones con la categorización del tipo de actividad turística. Existe una paleta cromática que vincula determina-
El color evoca recuerdos, asociados a experiencias o sensaciones vividas con anterioridad. También alude a ciertos aspectos culturales, con un carácter más subjetivo, o aspectos de la naturaleza, con un carácter más objetivo.

Un ejemplo común es la asociación del color blanco a la nieve, al invierno o al frío; por tanto, el turismo blanco se asocia al turismo invernal, generalmente asociado a deportes de invierno. En este caso,

11 Se trata de un método de observación que "se realiza sobre el entorno real del consumidor, que permite visualizar algunas situaciones o experiencias dentro de su diario vivir, y determinar de esta forma, aquellas variables o factores que pueden ser sensibles para ellos" (Zara y Tuta, 2013, citado en Muñoz Osores, 2015). 
dos colores con un tipo de turismo, tomando el patrón cultural como criterio de referencia. se asocia el color del medio natural al que se alude. Ocurre también con el turismo azul (asociado al mar y a los deportes náuticos) o el turismo verde (representa el turismo rural, aunque también se vincula al medioambiente, por lo que puede hacer referencia al ecoturismo o al turismo sostenible).

Como podemos observar, para poder tomar decisiones promocionales con un enfoque estratégico y una respuesta exitosa es necesario conocer, investigar y atender al consumidor y a su atención, emoción y memoria, así como la cultura en la que se enmarca. Todo ello resulta primordial para poder diseñar una técnica promocional que satisfaga las necesidades de consumo objetivo, que es en definitiva el motor que mueve toda actividad promocional, sea de la índole que sea.

Sin embargo, como apunta Fuentes Luque (2005: 60) con relación a la traducción de promoción turística,

[I]a traducción se muestra aquí como algo que con demasiada frecuencia queda limitado a lo lingüístico (o lo que es peor, a una mera equivalencia palabra por palabra, o imagen por imagen), pasando por alto factores clave como el grado de conocimiento que los potenciales lectores tienen acerca de la cultura origen, las expectativas de los lectores en cuanto a formato, presentación y contenido del texto publicitario, y la falta de información sobre las reacciones de los destinatarios, con las que reevaluar los textos y/o la marca-imagen traducidos.

En esta línea, Fuentes Luque (2005) expone, además, que el traductor turístico realmente debería actuar como "analista intercultural" (2005: 59) en tanto que, en su mediación entre la cultura origen y la cultura de destino, debe ser capaz de adaptar el mensaje no verbal (e, indudablemente, el mensaje verbal) al consumidor meta, para que pueda satisfacer sus estímulos con el fin de que la información sea percibida lingüística y sensorialmente del mismo modo en ambos contextos. En el caso de que el traductor no preste atención a dichos elementos multimodales y a su significado, ello supondría un distanciamiento del objetivo primordial del texto origen, la pérdida importante del contenido semiótico que caracteriza este tipo de textos, con la consiguiente ruptura de la comunicación sensorial con la mente del turista.

La heterogeneidad e interdisciplinariedad que caracterizan al lenguaje del turismo (Calvi, 2006) se evidencian también en el proceso traslativo de contenido turístico, que plantea indiscutiblemente la presencia y dominio de contenidos teóricos propios del ámbito publicitario y del neuromarketing y, al mismo tiempo, exige al traductor ir más allá de lo puramente lingüístico. El código semiótico visual adquiere un protagonismo especial que el traductor no puede desdeñar y, como hemos podido comprobar con la presente investigación, su incidencia en el trabajo de traducción es decisiva.

Por este motivo, resulta esencial que el traductor turístico sea capaz de identificar, comprender y caracterizar la estrategia promocional implementada y la funcionalidad de la imagen 
turística y la presencia del color en la misma dentro del discurso turístico. Este debe ser consciente de la dimensión cognitiva que transciende este código semiótico y, al mismo tiempo, ser capaz de emplear estos elementos con un mayor criterio interpretativo y creativo.

\section{Conclusión}

El presente trabajo de investigación nos ha permitido comprobar la incidencia del neuromarketing en los textos de promoción turística a través de la imagen y el código cromático. Por consiguiente, no cabe duda de que el traductor turístico deberá ser consciente de la importancia de conocer e identificar las estrategias de neuromarketing aplicables a un determinado colectivo con el fin de estimular sus sentidos, una apreciación necesaria para interpretar correctamente y a todos los niveles el mensaje objeto de traducción a una cultura meta determinada.

Traducir un contenido promocional turístico a otro idioma y destinado a un colectivo extranjero no familiarizado con la dimensión cultural del país de origen exige un conocimiento integral del comportamiento, necesidades, preferencias e intereses del consumidor-turista. Gracias a nuestro estudio hemos detectado que los textos turísticos promocionales tienen un significado sensorial que se materializa de forma efectiva a través de elementos visuales que contribuyen a una mejor comprensión de cualquier tipo de estímulo.

La exploración previa de la mente del consumidor permite racionalizar (o, al menos, interpretar) el modo en el que consumidor-turista percibe las emociones, el grado de empatía que genera y el modo en el que actúa ante los estímulos percibidos. Dilucidar dicho significado en la lengua origen y conseguir una presencia satisfactoria en la mente del usuario meta supone todo un reto para el traductor turístico.

A pesar de su naturaleza exploratoria, el presente trabajo proporciona evidencias concluyentes que podrían servir como base para una investigación complementaria. Profundizar en la dimensión práctica a través de un estudio empírico podría producir resultados interesantes y se plantea como investigación adicional para futuros estudios.

\section{Bibliografía citada}

Alonso Rivas, Javier, e Ildefonso Grande Esteban, 2013: Comportamiento del consumidor: decisiones y estrategia de marketing, Madrid: ESIC.

Azeglio, Armando, y José Manoel Gandara, 2010: "El estudio de la imagen de los destinos turísticos”, comunicación presentada en el VII Seminário da Associação Brasileira de Pesquisa e Pós-Graduação em Turismo, Universidade Anhembi Morumbi, São Paulo. 
Bergen, Benjamin K., 2014: El cerebro y el lenguaje: de las palabras a los hechos, Barcelona: RBA Libros.

Braidot, Néstor, y Pablo Braidot, 2006: Neuromarketing: neuroeconomía y negocios, Buenos Aires: PuertoNorte-Sur.

BRaidot, Néstor, 2000: ¿Por qué tus clientes se acuestan con otro si dicen que les gustas tú?, Barcelona: Gestión.

Calvano, Jose Luis, 2005: "Semiótica, cognición y comunicación visual: Ios signos básicos que construyen lo visible”, Tópicos del seminario 1 (13), 113-136.

Carvano, Jose Luis, 2001: "La investigación sobre los objetos visuales desde un punto de vista semiótico, con particular énfasis en los signos visuales producidos por la luz: color y cesía”, Cuadernos. Universidad de Jujuy, Argentina 16 (17), 85-89.

Calvano, Jose Luis, 1995, "Color y semiótica: un camino en dos direcciones", Cruzeiro Semiótico, 251-266.

Calvı, Maria Vittoria, 2006: Lengua y comunicación en el español del turismo, Madrid: Arco Libros.

Camprubi, Raquel, Jaume Guia y Jordi Comas, 2009: "La formación de la imagen turística inducida: un modelo conceptual”, PASOS. Revista de turismo y patrimonio cultural 7 (2), 255-270.

Conway, Bevil R., Soumya Chatterjee, Greg D. Field, Gregory D. Horwitz, Elizabeth N. Johnson, Kowa KoIDA y Katherine Mancuso, 2010: "Advances in color science: from retina to behavior", Journal of Neuroscience 30 (45), 14955-14963.

Dondis, Donis A., 1992: La sintaxis de la imagen. Introducción al alfabeto visual, Barcelona: Gili.

Ferrer Franquesa, Alba, y David Gómez Fontanills, 2013: Cultura y color, Barcelona: Universitat Oberta de Cataluña.

Fuentes LuQue, Adrián, 2005: "La traducción de promoción turística institucional: Ia proyección de la imagen de España” en Adrián Fuentes Luque (ed.): La traducción en el sector turístico, Granada: Comares, 59-92.

Gali Espelt, Nuria, y José Antonio Donalre, 2006: "La imagen percibida por los turistas de la ciudad de Girona”, Estudios Turísticos 168, 123-139.

Gallarza, Martina G., Irene Gil Saura, Haydée Calderón García, 2002: "Destination image: Towards a conceptual framework”, Annals of tourism research 29 (1), 56-78. 
GiBson, James Jerome, 1966: The Senses Considered as Perceptual Systems, Boston: Houghton Mifflin.

Gunn, Clare A., 1972: Vacationscape. Designing tourist regions, Austin: Taylor and Francis.

Hernández Ramírez, Javier, 2008: La imagen de Andalucía en el turismo, Sevilla: Centro de Estudios Andaluces.

Jannello, César V., 1984: Fundamentos de teoría de la delimitación, Buenos Aires: FAU-UBA.

KLARIC, Jürgen, 2016: “¿Qué es el neuromarketing?” [https://www.youtube.com/watch?V=25Y858ESBE, fecha de consulta: 10 de febrero de 2020].

KLARIC, Jürgen, 2015: Véndele a la mente, no a la gente, Barcelona: Planeta.

KRESS, Gunther, y Theo van LeEuwen, 2001: Discurso multimodal. Los modos y los medios de la comunicación contemporánea, Londres: Arnold.

LLoREns Simón, Eva María, 2017: “EEmpatía, persuasión y/o comunicación efectiva? Traducción y multimodalidad en el sector turístico. Mensajes corporativos en el ámbito del ocio y el tiempo libre”, E-Aesla 3, 290-310.

MacLean, Paul D., 1990: The triune brain in evolution: role in paleocerebral functions, New York: Plenum.

Magariños de Morentin, Juan, 2001: “La(s) semiótica(s) de la imagen visual”, Cuadernos de la Facultad de Humanidades y Ciencias Sociales. Universidad Nacional de Jujuy 17, 295-320.

Mıossec, Jean-Marie, 1977: “Un modèle de l'espace touristique”, L’Espace géographique, 41-48.

Muñoz Osores, Mauricio, 2015: “Conceptualización del Neuromarketing: Su Relación con el Mix de marketing y el comportamiento del consumidor (Conceptualisation of neuromarketing: its relationship with the Mix of marketing and consumer behavior)", RAN-Revista Academia \& Negocios 1 (2), 91-104.

PAGANI, Caroline, 2001: "Le variazioni antropologico-culturali dei significati simbolici dei colori”, Leitmotiv 1, 175-197.

PeARCE, Philip L., 1982: The social psychology of tourism behaviour, Nueva York: Pergamon.

PIKE, Steve, 2002: "Destination image analysis-a review of 142 papers from 1973 to 2000", Tourism management 23 (5), 541-549. 
Pritchard, Annette, y Nigel J. Morgan, 2001: "Culture, identity and tourism representation: marketing Cymru or Wales?”, Tourism management 22 (2), 167-179.

Ries, Al, y Jack Trout, 1994: Las 22 leyes inmutables del marketing, Londres: HarperCollins.

ReIman, Joey, 2001: Thinking for a Living: Creating Ideas That Revitalize Your Business, Career, and Life, Maryland: Taylor Trade Publishing.

SANTILLAN, Vilma Leonora, 2010: "La fotografía como creadora de la imagen de un destino turístico. Buenos Aires a través de sus tarjetas postales”, Pasos. Revista de turismo y patrimonio cultural 8 (1), 71-82.

Soler Guitián, Andrea, 2017: “Diseño emocional, una contribución a la sostenibilidad”, Economía Creativa 8, 55-83.

TAsCl, Asli D. A., William C. Gartner, 2007: "Destination image and its functional relationships", Journal of Travel Research 45 (4), 413-425.

VILASECA, Borja, 2006: “En la mente del consumidor”, El País [https://elpais.com/diario/2006/09/17/ negocio/1158500854_850215.html, fecha de consulta: 17 de marzo de 2020]. 